\title{
Homicide in Europe
}

\section{Marieke Liem and William Alex Pridemore}

Our aim with this Special Issue is to begin to fill an important empirical and academic gap in European criminological research: Homicide research in Europe. Relative to the United States and several commonwealth countries, Europe does not have a long tradition of studying the trends, patterns and explanations of homicide. Differences in legal definitions of and data sources on homicide have hampered cross-national comparisons. Further, population-level studies of homicide have long been at the periphery of criminological research, and this is especially true of European criminological scholarship. In light of these challenges, a small number of important recent initiatives have begun to systematically address homicide and homicide research in Europe.

First, the construction of the European Homicide Monitor (EHM) is enabling comparisons and analyses among European countries. So far, three countries constitute the basis of the database: Finland, the Netherlands and Sweden (Ganpat et al., 2011; Liem et al., 2013). Other European countries are now in the process of joining this exciting initiative, filling a long-existing lacuna. A homicide measurement project such as this is fundamental for further research that will provide evidence-based knowledge on topics such as the social factors that foster lethal violence, effective violence prevention, and setting rational punishment, sentencing policy and treatment of offenders. Second, the publication of our Handbook of European Homicide Research: Patterns, Explanations, and Country Studies (Liem and Pridemore, 2011) provided the first large-scale systematic collection of information on homicide research in Europe and serves as a foundation for research on the topic moving forward. Third, the increased activity of the European Homicide Research Group reveals an additional indication of the growing interest in this field.

We hope this Special Issue of the European Journal of Criminology represents yet another cornerstone to the growing field of European homicide research, and we thank the Journal's editor, Paul Knepper, and others at the European Journal of Criminology for their support. For this Special Issue, we sought to gather work concerned with various aspects of homicide and other serious violence to highlight these recent developments and the diversity of this research area. The articles here range from theory-based contributions, to empirical work making use of macro-level or national data, to data related to specific types of homicide. 
First, Kivivuori, Suonpää and Lehti provide a comprehensive overview of the status quo in theory-based European homicide research. The authors have identified dozens of articles via bibliometric and scientometric methods and examined patterns and trends in types of European homicide research, the theories that underlie this work, and the scholars who are it carrying out. They find that European homicide research is expanding, with research increasingly focusing on sub-types of homicide rather than homicide in general. Of these sub-types, intimate partner homicide appears to be among those drawing the most attention in Europe.

Aebi and Linde assess homicide trends in 15 West European countries and seek to explain these trends by drawing from four major criminological theories. These trends show an increase in homicide from the mid-1960s to the early 1990s, and a decrease since then. The authors point to the strong association between the general homicide rate and the male homicide rate. These trends, in short, seem driven by violence among young men in public spaces. The authors suggest that the development of the Internet since the 1990s has led to young people spending less time in public spaces, and this is associated with an overall declining trend in homicide.

The contributions by Stamatel and by Corradi and Stöckl focus on intimate partner homicide, further evidencing Kivivuori et al.'s observation of the growing interest in this area. Whereas Stamatel examines cross-national differences in the levels of female homicide across Europe, Corradi and Stöckl take a policy-based approach. Stamatel assesses whether cross-national differences in female homicide rates are due to the same factors that explain cross-national homicide variation more generally, if they are the product of differences in gender dynamics across these countries, or if they are reflections of regional differences capturing varying historical and cultural trajectories. From a policybased perspective, Corradi and Stöckl provide a comprehensive overview on policy development on intimate partner homicide and examine how these developments influence the occurrence of this type of homicide across Europe.

In the final two contributions, we move from the macro-European level to specific nations. Bänziger and Killias draw attention to the patterns and explanations of unsolved homicides in Switzerland. Making use of a national homicide database, the authors are able to assess a wide range of details on case, victim and offender characteristics. Such analyses are unique, because the police statistics normally employed for such analyses typically lack such detailed information. Even though some of their findings correspond to US studies - in that victim characteristics and case circumstances influence homicide clearance rates similarly to in the US - they also find that in Switzerland the use of a firearm increases, rather than decreases, the likelihood that a homicide will be solved.

The homicide type that arguably most strikes the public's imagination is serial murder. Hall and Wilson use serial murder in the United Kingdom to build the groundwork for an integrated multi-level theory of homicide. Their theoretical foundation includes the broader political, economic and cultural forces that shape specific locations that are attractive to both perpetrators and victims of violence, and it connects these forces and spaces with individual motivations for violence. Together with the other unique contributions in this issue, we believe that this work will further accelerate the breadth and depth of ideas as European homicide research advances and matures. 


\section{References}

Ganpat S, Granath S, Kivivuori J, Lehti M, Liem M and Nieuwbeerta P (2011) Homicide in Finland, the Netherlands and Sweden: A First Study on the European Homicide Monitor Data. Brottsförebyggande rådet/The Swedish National Council for Crime Prevention.

Liem M, Ganpat S, Granath S, Hagstedt J, Kivivuori J, Lehti M and Nieuwbeerta P (2013) Homicide in Finland, the Netherlands, and Sweden: First findings from the European Homicide Monitor. Homicide Studies 17(1): 75-95.

Liem M and Pridemore WA (eds) (2011) Handbook of European Homicide Research: Patterns, Explanations, and Country Studies. New York: Springer. 